\title{
Epi-trichosetin, a new undecaprenyl pyrophosphate synthase inhibitor, produced by Fusarium oxysporum FKI-4553
}

\author{
Junji Inokoshi ${ }^{1}$, Naoki Shigeta ${ }^{1}$, Takashi Fukuda ${ }^{1}$, Ryuji Uchida ${ }^{1}$, Kenichi Nonaka ${ }^{2}$, Rokurou Masuma ${ }^{2}$ \\ and Hiroshi Tomoda ${ }^{1}$
}

A new compound, designated epi-trichosetin (1), was isolated along with the known compound trichosetin (2) from the culture broth of Fusarium oxysporum FKI-4553 by solvent extraction, silica gel column chromatography and reversed-phase HPLC. The structure of 1 was elucidated by comparing various spectral data with those of 2 , revealing that 1 was a stereoisomer of 2 . Compounds 1 and 2 inhibited the undecaprenyl pyrophosphate synthase activity of Staphylococcus aureus with $\mathrm{IC}_{50}$ values of 83 and $30 \mu \mathrm{m}$, respectively, and showed antimicrobial activity, particularly against Gram-positive bacteria, including methicillin-sensitive and -resistant $S$. aureus.

The Journal of Antibiotics (2013) 66, 549-554; doi:10.1038/ja.2013.44; published online 29 May 2013

Keywords: epi-trichosetin; Fusarium oxysporum FKI-4553; undecaprenyl pyrophosphate synthase inhibitor

\section{INTRODUCTION}

Antibiotic-resistant bacterial infections pose a major threat to public health. Methicillin-resistant Staphylococcus aureus (MRSA) is recognized as a major nosocomial pathogen that has also developed resistance to many other antibiotics, such as other $\beta$-lactams. ${ }^{1}$ Moreover, MRSA resistant to the last-resort antibiotic, vancomycin, has been reported. ${ }^{2}$ This suggests that $S$. aureus will acquire full resistance to vancomycin in the future. However, the past 30 years have seen only two new classes of antibiotics introduced into clinical use, represented by the natural product daptomycin ${ }^{3}$ and the synthetic oxazolidinone linezolid; ${ }^{4}$ therefore, there is a great need for the discovery and development of new anti-infective agents possessing novel mechanisms of action.

The bacterial cell wall is an attractive target for antibacterial agents because it is an essential, bacterial-specific structure that is absent in human cells. ${ }^{5}$ Undecaprenyl pyrophosphate (UPP) is a key lipid involved in the biosynthesis of peptidoglycan and other cell wall polysaccharide components such as lipopolysaccharides, enterobacterial common antigens, capsule polysaccharides and teichoic acids. UPP-linked saccharides are also used for $\mathrm{N}$-linked protein glycosylation, which occurs in certain prokaryotes. In the cell wall synthetic pathway, UPP is needed for the synthesis and transport of hydrophilic GlcNAc-MurNAc pentapeptides across the hydrophobic environment of the cytoplasmic membrane to externally located sites of polymerization. Thus, UPP synthase inhibitors that cause specific growth inhibition against bacteria, including MRSA or vancomycin-resistant $S$. aureus, are anticipated to be useful clinical drugs because such inhibitors have yet to be used in the clinical or agricultural fields.

On the basis of this concept, screening for UPP synthase inhibitors of microbial origin was carried out, and spirohexaline and viridicatumtoxin were isolated and identified from a culture of Penicillium brasilianum FKI-3368. ${ }^{6}$ During the course of our continued screening program, a new compound, designated epi-trichosetin (1) (Figure 1), was isolated from the culture broth of Fusarium oxysporum FKI-4553 along with a known antibiotic, trichosetin (2). ${ }^{7}$ In this study, we describe the taxonomy of the producing fungus, and the fermentation, isolation, structure elucidation and activity of these trichosetins.

\section{RESULTS}

Taxonomy

Colonies on potato dextrose agar (PDA) were $72-74 \mathrm{~mm}$ in diameter after 7 days at $25^{\circ} \mathrm{C}$ (Figure 2a), floccose, plane to subelevated, with white (1A1) to lilac (15B4) mycelium; the reverse was orange white (5A2) to dark violet (15F7). Colony margin was entire; exudate and soluble pigment were not produced. Colonies on synthetic low-nutrient agar (SNA) were more than $85 \mathrm{~mm}$ in diameter after 7 days at $25^{\circ} \mathrm{C}$, floccose, plane, with colorless to white (1A1) mycelium; exudate and soluble pigment were not produced. Colonies on PDA at 5 and $37^{\circ} \mathrm{C}$ were not produced. Chlamydospores were formed frequently in hyphae and in conidia, mostly subglobose and single. Sclerotia were absent. Sporulation was generally rapid. Aerial conidia were of two types: (1) 3(-4)-septate conidia were curved 
cylindrical to falcate, $(20-) 25-52 \times 3.8-6.0(-7.0) \mu \mathrm{m}^{2}$ (Figure $2 \mathrm{~b}$ ); (2) $0(-1)$-septate conidia were minute, obovate, short clavate to ellipsoidal, (4.3-)5.0-13.5 $\times 1.5-3.5 \mu \mathrm{m}^{2}$ (Figure 2c). Conidiogenesis of $3(-4)$-septate conidia and $0(-1)$-septate conidia was phialidic. From the above morphological characteristics, strain FKI-4553 was considered to belong to the genus Fusarium. In a BLAST search using blastn from the National Center for Biotechnology Information, ${ }^{8}$ FKI-4553 had $100 \%$ similarity with the internal transcribed spacer (ITS) sequences of F. oxysporum NRRL 22902 (GenBank accession number U34566). From these results of morphological characteristics and the homology searching using blastn, the producing strain FKI-4553 was identified with F. oxysporum.

\section{Fermentation}

A slant culture of $F$. oxysporum FKI-4553 grown on LCA medium $\begin{array}{llllll}0.1 \% & \text { glycerol, } & 0.08 \% & \mathrm{KH}_{2} \mathrm{PO}_{4}, \quad 0.02 \% & \mathrm{~K}_{2} \mathrm{HPO}_{4}, \quad 0.02 \%\end{array}$ $\mathrm{MgSO}_{4} \cdot 7 \mathrm{H}_{2} \mathrm{O}, 0.02 \% \mathrm{KCl}, 0.2 \% \mathrm{NaNO}_{3}, 0.02 \%$ yeast extract and $1.5 \%$ agar, adjusted to $\mathrm{pH} 6.0$ before sterilization) was inoculated into a $500-\mathrm{ml}$ Erlenmeyer flask containing $100 \mathrm{ml}$ of the seed medium (2.0\% glucose, $0.5 \%$ polypeptone, $0.05 \% \mathrm{MgSO}_{4} \cdot 7 \mathrm{H}_{2} \mathrm{O}, 0.2 \%$ yeast extract, $0.1 \% \mathrm{KH}_{2} \mathrm{PO}_{4}$ and $0.1 \%$ agar, adjusted to $\mathrm{pH} 6.0$ before sterilization). The flask was incubated on a rotary shaker (270 r.p.m.) for 3 days at $27^{\circ} \mathrm{C}$ to obtain the seed culture. The production culture was initiated by transferring the seed culture $(2 \mathrm{ml})$ into a $500-\mathrm{ml}$ Erlenmeyer flask containing $100 \mathrm{ml}$ of the production medium $(3.0 \%$ soluble starch, $1.0 \%$ glycerol, $2.0 \%$ soybean meal, $0.3 \%$ dry yeast, $0.3 \% \mathrm{KCl}, 0.2 \% \quad \mathrm{CaCO}_{3}, 0.05 \% \mathrm{MgSO}_{4} \cdot 7 \mathrm{H}_{2} \mathrm{O}, 0.05 \% \quad \mathrm{KH}_{2} \mathrm{PO}_{4}$, adjusted to $\mathrm{pH} 6.0$ before sterilization) and fermentation was carried out at $27^{\circ} \mathrm{C}$ for 7 days. UPP synthase inhibitory activity was detected in the culture broth from day 3 after inoculation. The activity reached a maximal level on day 5 and kept almost the same levels at least on day 7.

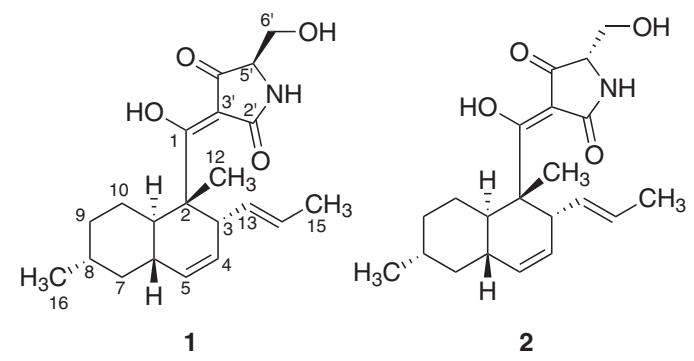

Figure 1 Structures of epi-trichosetin (1) and trichosetin (2).

\section{Isolation}

The 7-day-old whole culture (3.8l) was extracted with acetone (4.01). After the acetone extracts had been filtered and concentrated to remove acetone, the aqueous solution (31) was extracted twice with ethyl acetate (1.5l). The extracts were dried over $\mathrm{Na}_{2} \mathrm{SO}_{4}$ and concentrated in vacuo to dryness to yield brown oily materials. The material $(0.9 \mathrm{~g})$ was dissolved in a small amount of $\mathrm{CHCl}_{3}$ and applied to a silica gel column (i.d. $3.6 \times 20 \mathrm{~cm}$, silica gel 60 , 70-230 mm; Merck KgaA, Darmstadt, Germany) previously equilibrated with $\mathrm{CHCl}_{3}$, and eluted stepwise with $\mathrm{CHCl}_{3}-\mathrm{MeOH}(200 \mathrm{ml}$ each, 100:0, 9:1, 5:1, 2:1 and 0:100). The fractions of $\mathrm{CHCl}_{3}-\mathrm{MeOH}$ (5:1 and 2:1) were combined and concentrated in vacuo to dryness to give dark-brown material $(145 \mathrm{mg})$. The material was finally purified by preparative HPLC (column, CAPCELL PAK C18, $\phi 20 \times 250 \mathrm{~mm}$; Shiseido Co Ltd, Tokyo, Japan; solvent, $62 \% \mathrm{CH}_{3} \mathrm{CN}$ containing $0.05 \%$ trifluoroacetic acid (TFA); detection, UV at $210 \mathrm{~nm}$; flow rate, $8.0 \mathrm{ml} \mathrm{min}^{-1}$ ). Under these conditions, 1 and 2 were eluted as peaks with retention times of 39.2 and $36.3 \mathrm{~min}$, respectively. The fractions were concentrated in vacuo to dryness to give pure $\mathbf{1}(2.0 \mathrm{mg})$ and $\mathbf{2}$ (10.5 mg) as colorless materials.

\section{Physicochemical properties}

The physicochemical properties of $\mathbf{1}$ and $\mathbf{2}$ are summarized in Table 1. The UV spectra of these compounds showed similar absorption maxima at 250 and $288 \mathrm{~nm}$ or 249 and $289 \mathrm{~nm}$, respectively, indicating very close structural relationship.

\section{Structure elucidation}

The molecular formula of epi-trichosetin (1) was determined to be $\mathrm{C}_{21} \mathrm{H}_{29} \mathrm{NO}_{4}$ on the basis of HRESI-TOF-MS measurement (Table 1). The ${ }^{13} \mathrm{C}$ NMR spectrum (in $\mathrm{CDCl}_{3}$ ) showed 21 resolved signals, which were classified into three methyl carbons, four methylene

Table 1 Physicochemical properties of epi-trichosetin (1) and trichosetin (2)

\begin{tabular}{lcc}
\hline & 1 & 2 \\
\hline Appearance & Colorless powder & Colorless powder \\
Molecular weight & 359 & 359 \\
Molecular formula & $\mathrm{C}_{21} \mathrm{H}_{29} \mathrm{NO}_{4}$ & $\mathrm{C}_{21} \mathrm{H}_{29} \mathrm{NO}_{4}$ \\
HRESI-TOF-MS (m/z) & & \\
Calculated: & $358.2018(\mathrm{M}-\mathrm{H})^{-}$ & $358.2018(\mathrm{M}-\mathrm{H})^{-}$ \\
Found: & $358.1903(\mathrm{M}-\mathrm{H})^{-}$ & $358.1900(\mathrm{M}-\mathrm{H})^{-}$ \\
UV(MeOH) $\lambda \max (\mathrm{nm})(\varepsilon)$ & $249(62800)^{-}$ & $250(58500)^{-}$ \\
& $289(96900)^{-}$ & $288(98000)^{-}$ \\
{$[\alpha]_{\mathrm{D}}^{26}(c=0.1, \mathrm{MeOH})$} & $-233^{\circ}$ & $-413^{\circ}$ \\
$\mathrm{CD}(\mathrm{MeOH}) \lambda \mathrm{nm}(\mathrm{Mol} . \mathrm{CD})$ & $238(0.17), 272(-5.5)$ & $230(-4.6), 277(-8.2)$ \\
\end{tabular}
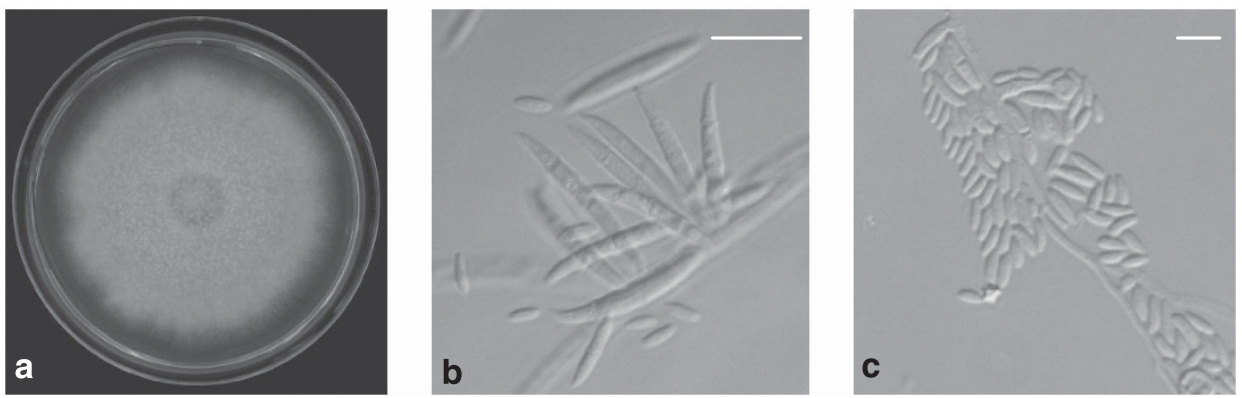

Figure 2 F. oxysporum FKI-4553. (a) Photograph of colonies grown on PDA after 7 days. (b) Micrograph of 3-4 septate conidia grown on SNA. (c) Micrograph of 0-1 septate conidia grown on SNA. Scale bars: (b) $20 \mu \mathrm{m}$; (c) $10 \mu \mathrm{m}$. A full color version of this figure is available at The Journal of Antibiotics journal online. 
carbons, nine (four $s p^{2}$ ) methine carbons, three (two $s p^{2}$ ) quaternary carbons and two carbonyl carbons by analysis of DEPT spectra. The ${ }^{1} \mathrm{H}$ NMR spectrum (in $\mathrm{CDCl}_{3}$ ) showed three methyl signals, five methylene signals and nine methine signals. The connectivity of proton and carbon atoms was established by the HMQC spectrum, as shown in Table 2. Analysis of the ${ }^{1} \mathrm{H}-{ }^{1} \mathrm{H}$ COSY spectrum gave connectivity from C-3 to C-15 (Figure 3). Additional analysis of the $\mathrm{HMBC}$ experiments gave the following information. The cross peaks from $\mathrm{H}_{3}-12(\delta 1.46)$ to $\mathrm{C}-1(\delta 200.8), \mathrm{C}-2(\delta 49.3), \mathrm{C}-3(\delta 45.2)$ and C-11 $(\delta 40.2)$ supported the partial structure I. The cross peaks from $5^{\prime}-\mathrm{H}(\delta 3.89)$ to $\mathrm{C}-2^{\prime}(\delta 179.5)$ and $\mathrm{C}-3^{\prime}(\delta 100.3)$ and from $6^{\prime}-\mathrm{H}_{2}$ $(\delta 3.79,3.88)$ to $\mathrm{C}-4^{\prime}(\delta 191.1)$ supported the partial structure II. From

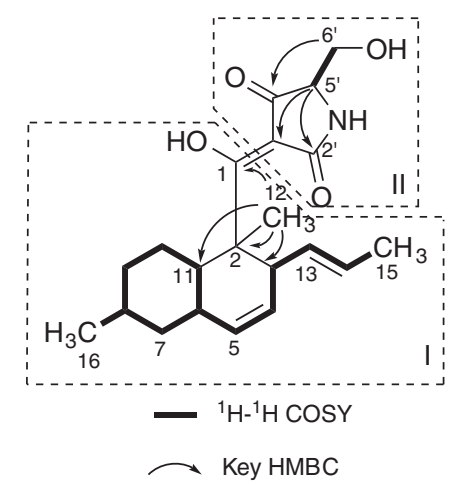

Figure 3 Key correlations in ${ }^{1} \mathrm{H}-{ }^{1} \mathrm{H}$ COSY and $\mathrm{HMBC}$ spectra of 1 . all these data and the results of searching the Chapman and Hall Dictionary of Natural Products database, ${ }^{9}$ the planar structure of 1 was elucidated to be the same as the known trichosetin (2).

The clear point of difference between $\mathbf{1}$ and $\mathbf{2}$ is the absolute value of optical rotation. The value of $[\alpha]_{\mathrm{D}}^{26}$ of 1 was $-233^{\circ}$ in $\mathrm{MeOH}$, whereas that of 2 was $-413^{\circ}$, suggesting that 1 and 2 were stereoisomers. To elucidate the stereochemistry of 1 , ROESY experiments were carried out (Figure 4). Observation of the ROESY correlations between $\mathrm{H}-8 \mathrm{ax}(\delta 1.50)$ and $\mathrm{H}-6 \mathrm{ax}(\delta 1.84)$, between H-6ax and $\mathrm{H}_{3}-12(\delta 1.46)$, between $\mathrm{H}_{3}-12$ and $\mathrm{H}-10 \mathrm{ax}(\delta 1.05)$, and

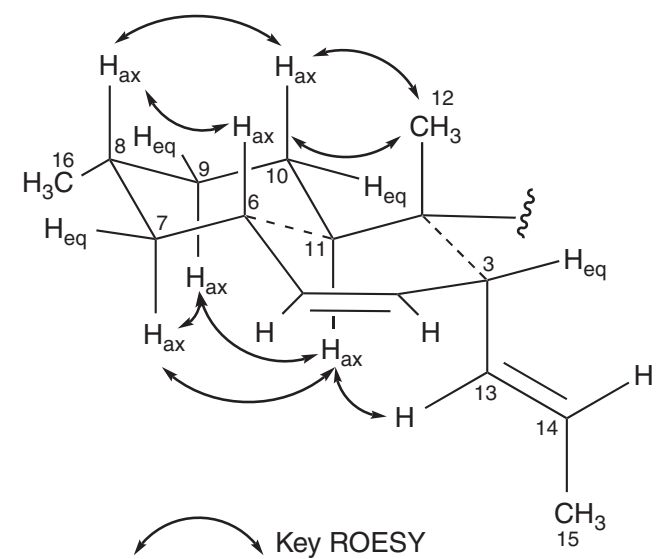

Figure 4 Key ROESY correlations of 1 .

Table $2{ }^{1} \mathrm{H}$ and ${ }^{13} \mathrm{C}$ NMR chemical shifts of 1 and 2

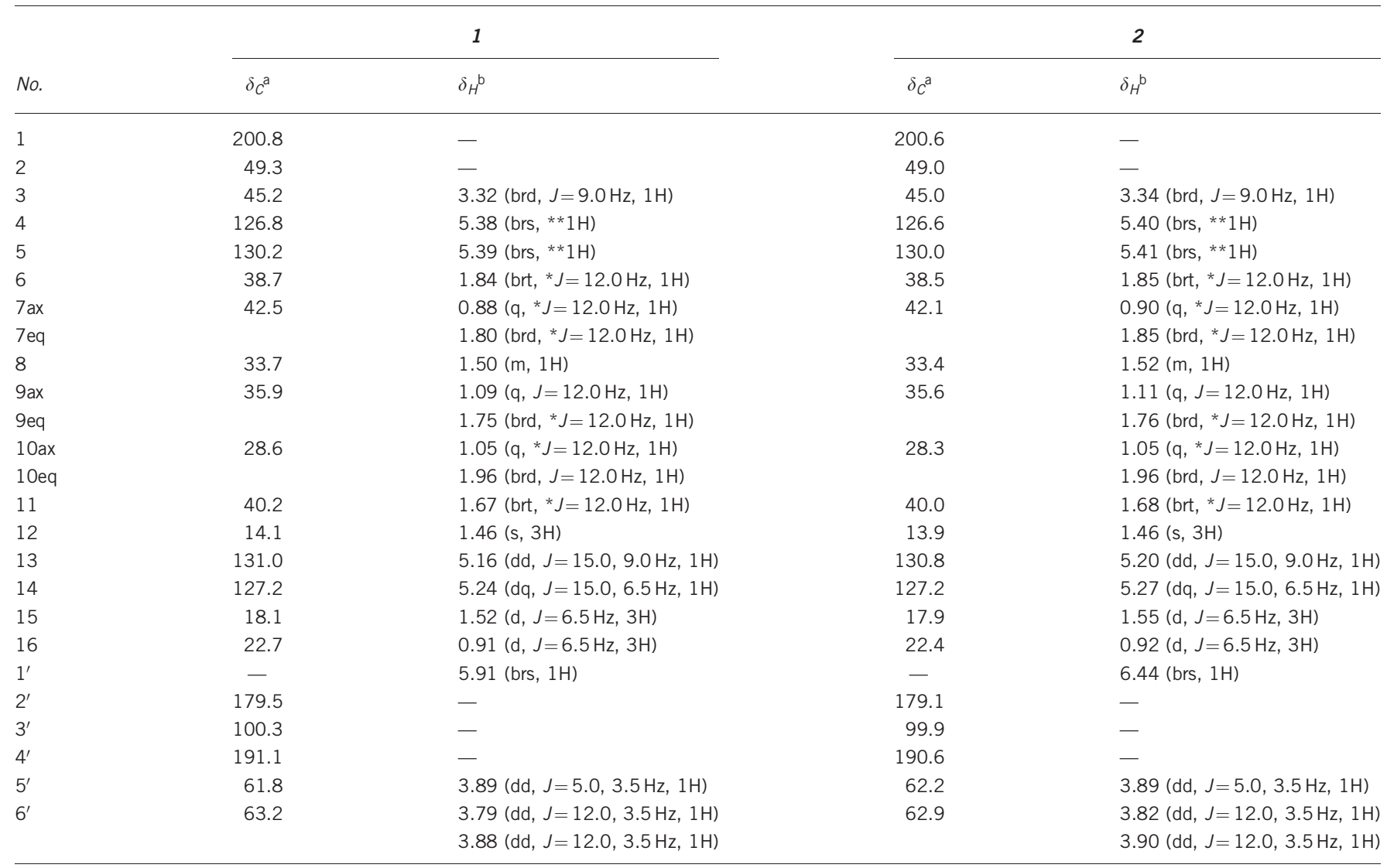




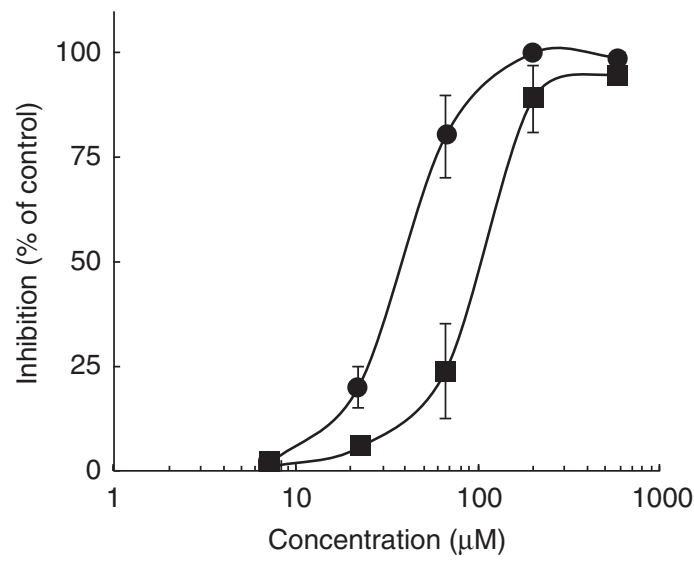

Figure 5 Inhibition of UPPS by $\mathbf{1}(\mathbf{\square})$ and $\mathbf{2}(\bullet)$. Prenylsynthase activity was determined to measure the amount of free phosphate by an enzymecoupling fluorescent method, as described in the General experimental procedure. Error bars: \pm s.d. $(n=4)$.

Table 3 Antimicrobial activity of 1 and 2

\begin{tabular}{|c|c|c|}
\hline \multirow[b]{2}{*}{ Test organism } & \multicolumn{2}{|c|}{ Inhibition zone $(\mathrm{mm})^{\mathrm{a}}$} \\
\hline & 1 & 2 \\
\hline \multicolumn{3}{|l|}{ Gram-positive bacteria } \\
\hline Staphylococcus aureus ATCC 6538P (MSSA) & 18 & 15 \\
\hline S. aureus K24 (MRSA) & 16 & 14 \\
\hline Bacillus subtilis $\mathrm{PCl} 219$ & 18 & 16 \\
\hline Micrococcus luteus PCl 9341 & 17 & 15 \\
\hline Mycobacterium smegmatis ATCC 607 & 9 & 8 \\
\hline \multicolumn{3}{|l|}{ Gram-negative bacteria } \\
\hline Escherichia coli NIHJ & 10 & 10 \\
\hline Pseudomonas aeruginosa IFO 3080 & - & - \\
\hline Xanthomonas campestris KB 88 & 9 & 7 \\
\hline Bacteroides fragilis ATCC 23745 & 11 & 11 \\
\hline \multicolumn{3}{|l|}{ Mycoplasma } \\
\hline Acholeplasma laidlawii KB 174 & 12 & 9 \\
\hline \multicolumn{3}{|l|}{ Molds } \\
\hline Pyricularia oryzae KF 180 & 14 & 11 \\
\hline Aspergillus niger ATCC 9642 & - & - \\
\hline Mucor racemosus IFO 4581 & 7 & 7 \\
\hline \multicolumn{3}{|l|}{ Yeasts } \\
\hline Candida albicans ATCC 64548 & - & - \\
\hline Saccharomyces cerevisiae ATCC 9763 & - & - \\
\hline
\end{tabular}

Abbreviations: MRSA, methicillin-resistant Staphylococcus aureus. a Concentration of the sample; $10 \mu \mathrm{g}$ per $6 \mathrm{~mm}$ paper disk. between $\mathrm{H}-8 \mathrm{ax}$ and $\mathrm{H}-10 \mathrm{ax}$ in $\mathbf{1}$ suggested that all these protons were located on the same side of the molecule. Similarly, H-7ax $(\delta 0.88)$, H-9ax $(\delta 1.09), \mathrm{H}-11(\delta 1.67)$ and H-13 ( $\delta 5.16)$ were located on the other side of the molecule. From these results, the absolute configuration of 1 was determined as $2 S, 3 S, 6 S, 8 R, 11 R$ (Figure 4). The structural difference between 1 and 2 was derived from the stereochemistry at $\mathrm{C}-5^{\prime}$. In fact, the chemical shifts at $1^{\prime}-\mathrm{NH}$ were distinct ( $\delta 5.91$ for 1 and $\delta 6.44$ for 2 ), indicating that $C-5^{\prime}$ in 1 should be $R$ because 2 was reported to have $S$ stereochemistry. ${ }^{7}$ Taken together, the absolute configuration of 1 was elucidated to be $2 S, 3 S, 6 S, 8 R, 11 R$, $5^{\prime} R$. Thus, 1 was the epimer of 2 at $\mathrm{C}-5^{\prime}$.

\section{Biological properties}

UPP synthase activity. UPP synthase activity was measured by the enzyme-coupled fluorescent method. ${ }^{10}$ Compounds $\mathbf{1}$ and 2 inhibited UPP synthase activity, with $\mathrm{IC}_{50}$ values of 83 and $30 \mu \mathrm{M}$, respectively (Figure 5).

Antimicrobial activity. As $\mathbf{1}$ and 2 showed moderate inhibition of UPP synthase, it was interesting to see whether they showed antimicrobial activity. Table 3 summarizes the results by the paper disk method. Compounds $\mathbf{1}$ and $\mathbf{2}$ showed broad antibacterial activity, in particular, potent activity against Gram-positive bacteria, including methicillin-sensitive S. aureus (ATCC 6538P, MSSA) and -resistant S. aureus (K24, MRSA). Compound 1 appeared more potent than 2 by this method.

\section{DISCUSSION}

F. oxysporum FKI-4553 produced two structurally related compounds 1 and 2 at an approximate ratio of 1:5. The structure of 1 was elucidated by comparing its spectral data with those of 2 . Careful comparison enabled us to conclude that $\mathbf{1}$ was the epimer of $\mathbf{2}$ at C-5'. Several structurally related compounds, such as equisetin (3), ${ }^{11}$ paecilosetin (4), ${ }^{12}$ and phomasetin (5), ${ }^{13}$ were isolated from fungal strains belonging to the genera Fusarium, Phoma and Paecilomyces, respectively (Figure 6). All compounds having a tetramic acid moiety are known to show a variety of biological activities, such as antimicrobial activity, ${ }^{14}$ phytotoxic activity ${ }^{15}$ and inhibitory activity of HIV integrase. ${ }^{13,16,17}$ From the present study, it is plausible that antimicrobial activity of $\mathbf{1}$ and $\mathbf{2}$ (Table 3 ) was caused by the inhibition of UPP synthase. However, these compounds also inhibited fungal growth. It might be that a tetramic acid has potential to bind to various proteins, including UPP synthase-related fungal enzymes such as dehydrodolichyl diphosphate synthase, ${ }^{18}$ leading to a variety of biological activities.<smiles>C/C=C/[C@H]1C=C[C@H]2C[C@H](C)CC[C@H]2[C@]1(C)/C(O)=C1\C(=O)[C@@H](CO)N(C)C1=O</smiles>

3<smiles>C/C=C/[C@H]1C=C[C@H]2C[C@H](C)CCC2[C@@]12CC2/C(O)=C1\C(=O)N[C@H](C(C)O)C1=O</smiles>

4<smiles>C/C=C/C=C/[C@H]1C=CC2CC(C)CC[C@H]2[C@H]1/C(C)=C(/O)C1C(=O)C(CO)N(C)C1=O</smiles>

Figure 6 Structures of equisetin (3), paecilosetin (4) and phomasetin (5). 
At first, 1 was thought to be an artifact from 2, because Phillips et al. ${ }^{19}$ reported the possibility of epimerization of equisetin by pyridine treatment, but pyridine was not used during the isolation process from the culture broth. From the study of trichosetin biosynthesis, ${ }^{20} 2$ was produced via the polyketide pathway, and C-5' was derived from serine. ${ }^{21}$ Therefore, the polyketide synthase for 2 might recognize $\mathrm{D} / \mathrm{L}$-serine or possess epimerase activity; however, we cannot rule out that $\mathbf{1}$ is an artifact of 2 . This point will be clarified by the functional analysis of the biosynthetic genes of natural products involved in the tetramic acid moiety.

\section{MATERIALS AND METHODS}

\section{Bacterial strains, plasmid, enzymes and chemicals}

F. oxysporum FKI-4553 was used for the production of $\mathbf{1}$ and $\mathbf{2}$.

The Escherichia coli strains used for the production of the recombinant UPP synthase were JM109 (Takara Bio Inc, Shiga, Japan) and BL21 (DE3) (Merck KGaA). The strains were grown in Luria-Bertani medium (Becton Dickinson and Company, Franklin Lakes, NJ, USA), with aeration at $37^{\circ} \mathrm{C}$. Microorganisms used for measurement of antimicrobial activity were as follows: Bacillus subtilis PCl 219, S. aureus ATCC 6538P, S. aureus K24 (MRSA), Micrococcus luteus $\mathrm{PCl}$ 9341, Mycobacterium smegmatis ATCC 607, E. coli NIHJ, Pseudomonas aeruginosa IFO 3080, Xanthomonas campestris KB 88, Bacteroides fragilis ATCC 23745, Acholeplasma laidlawii KB 174, Pyricularia oryzae KF 180, Aspergillus niger ATCC 9642, Mucor racemosus IFO 4581, Candida albicans ATCC 64548 and Saccharomyces cerevisiae ATCC 9763.

Plasmid pET-42b $(+)$ was from Novagen (Abingdon, England). Restriction enzymes were from New England Biolabs (Beverly, MA, USA) or Takara Bio Inc, and were used as specified by the manufacturers. Amplex red was from Invitrogen (Carlsbad, CA, USA). $\left[1-{ }^{14} \mathrm{C}\right]$ IPP $\left(1.48 \mathrm{GBq} \mathrm{mmol}^{-1}\right)$ was from PerkinElmer (Waltham, MA, USA). The precoated reversed-phase TLC plate, RP-18, was from GE Healthcare (Buckinghamshire, UK). All other chemicals were from Sigma (St Louis, MO, USA).

\section{General experimental procedures}

SSC-ODS-7515-12 (Senshu Scientific Co, Tokyo, Japan) was used for the reversed-phase (C18) HPLC. HPLC was carried out using the L-6200 system (Hitachi Ltd, Tokyo, Japan). UV spectra were recorded on a spectrophotometer (8453 UV-Visible spectrophotometer; Agilent Technologies Inc, Santa Clara, CA, USA). Optical rotations were measured with a digital polarimeter (DIP-1000; JASCO, Tokyo, Japan). HR-ESI-TOF-mass spectra were recorded on a mass spectrometer (JMS-T100LP; JEOL, Tokyo, Japan). Various NMR spectra were measured with a spectrometer (XL-400; Agilent Technologies, Inc., Loveland, CO, USA).

\section{Taxonomic studies of the producing organism}

Fungal strain FKI-4553 was isolated from soil collected in Yamaguchi City, Yamaguchi Pref., Japan. For determination of the morphological characteristics, the isolate was inoculated as a one-point culture on PDA and SNA, and kept at $25^{\circ} \mathrm{C}$ for 7 days (also at 5 and $37^{\circ} \mathrm{C}$ on PDA) in the dark. The Methuen Handbook of Color was used to determine color names and hue numbers. ${ }^{22}$ For the determination of micro-morphological characteristics, microscope slides were prepared using SNA. The slides were examined with a Vanox-S AH-2 microscope (Olympus, Tokyo, Japan).

Genomic DNA of fungal strain FKI-4553 was isolated using PrepMan Ultra Sample Preparation Reagent (Applied Biosystems, Foster City, CA, USA), following the manufacturer's instructions. Amplification of the ribosomal RNA gene (rDNA) ITS region including the 5.8S rDNA was performed using primers ITS1 and ITS4. ${ }^{23}$ Amplifications were performed in a PCR Verity 96-well thermal cycler (Applied Biosystems) and the PCR products were purified using a QIAquick, PCR DNA Purification (Qiagen Inc, Valencia, CA, USA), following the manufacturer's instructions. The PCR products were sequenced using a BigDye Terminator v3.1 Cycle Sequencing Kit (Applied Biosystems). Sequencing products were purified using a BigDye XTerminator (Applied Biosystems), and samples were analyzed on an ABI PRISM 3130 Genetic Analyzer (Applied Biosystems). Contigs were assembled using the forward and reverse sequences with the SeqMan and SeqBuilder programs from the Lasergene 9 package (DNAStar Inc, Madison, WI, USA). The ITS sequences of the strain FKI-4553 were deposited in DNA Data Bank of Japan with the accession number AB685181.

\section{UPP synthase assay}

UPP synthase activity was measured as described elsewhere. ${ }^{6,10}$ In brief, reactions were performed in black 96-well plates from DS Pharma Biomedical Co, Ltd (Osaka, Japan). UPP synthase was incubated at $37^{\circ} \mathrm{C}$ with $5 \mathrm{mU}$ of inorganic pyrophosphatase from Saccharomyces cerevisiae in a total reaction volume of $100 \mu \mathrm{l}$ containing $100 \mathrm{~mm}$ Tris- $\mathrm{HCl}(\mathrm{pH} 7.5), 0.5 \mathrm{~mm} \mathrm{MgCl}, 50 \mathrm{~mm}$ $\mathrm{KCl}, 3.5 \mu \mathrm{M} \mathrm{M}$ isopentenyl pyrophosphate, $0.5 \mu \mathrm{m}$ farnesyl pyrophosphate and $0.005 \%$ (wt/vol) Triton X-100. The reaction was terminated after $30 \mathrm{~min}$ by the addition of $10 \mu \mathrm{l}$ of $0.5 \mathrm{M}$ EDTA and quenched with $100 \mu \mathrm{l}$ of a cocktail containing $100 \mathrm{~mm}$ Tris- $\mathrm{HCl}\left(\mathrm{pH}\right.$ 7.4), $3 \mathrm{~mm}$ inosine, $0.2 \mathrm{mUml}^{-1} \mathrm{PNP}$, $10 \mathrm{mU} \mathrm{ml}^{-1} \mathrm{HRP}, 4 \mathrm{mU} \mathrm{ml}^{-1} \mathrm{XOD}$ and $0.1 \mathrm{~mm}$ Amplex red. After another $30 \mathrm{~min}$ of incubation at room temperature, the plate was read at $530 / 590 \mathrm{~nm}$. The amount of phosphate released from IPP was calculated from a standard curve prepared with $\mathrm{KH}_{2} \mathrm{PO}_{4}$.

\section{Antimicrobial assays}

Antimicrobial activity against 15 species of microorganisms was measured by the paper disk method. ${ }^{24}$ Media for microorganisms were as follows: nutrient agar (Sanko Junyaku Co, Ltd, Tokyo, Japan) for the bacteria, except $M$. smegmatis; a medium composed of $0.5 \%$ peptone, $0.5 \%$ meat extract, $0.3 \% \mathrm{NaCl}, 1.0 \%$ glucose and $0.8 \%$ agar for $M$. smegmatis; a medium composed of $1.0 \%$ glucose, $0.5 \%$ yeast extract and $0.8 \%$ agar for fungi and yeasts. Bacteria, except $X$. oryzae, were incubated at $37^{\circ} \mathrm{C}$ for $24 \mathrm{~h}$. Yeasts, A. niger and $X$. oryzae, were incubated at $27^{\circ} \mathrm{C}$ for $24 \mathrm{~h}$. P. oryzae and M. racemosus were incubated at $27^{\circ} \mathrm{C}$ for $48 \mathrm{~h}$. B. fragilis was incubated under anaerobic conditions. A paper disk $(6 \mathrm{~mm})$ containing a sample $(10 \mu \mathrm{g})$ was placed on an agar plate. Antimicrobial activity of a sample was expressed as the diameter $(\mathrm{mm})$ of the inhibitory zone.

\section{ACKNOWLEDGEMENTS}

We wish to thank Dr K. Nagai and Ms N. Sato (Kitasato University) for measurements of mass spectra and NMR, respectively.

1 Centers for Disease Control and Prevention (CDC). Staphylococcus aureus with reduced susceptibility to vancomycin-United States. Morb. Mortal. Wkly. Rep 46, 765-766 (1997).

2 Hiramatsu, K. et al. Methicillin-resistant Staphylococcus aureus clinical strain with reduced vancomycin susceptibility. J. Antimicrob. Chemother. 40, 135-136 (1997).

3 Fowler, V. G. Jr et al. Daptomycin versus standard therapy for bacteremia and endocarditis caused by Staphylococcus aureus. N. Engl. J. Med. 355, 653-665 (2006).

4 Irinoda, K., Nomura, S. \& Hashimoto, M. Antimicrobial and clinical effect of linezolid (ZYVOX), new class of synthetic antibacterial drug. Nihon. Yakurigaku. zasshi. 120, 245-252 (2002) in Japanese.

5 Walsh, C. T. Antibiotics: Actions, Origins, Resistance (ASM Press, Washington, DC, 2003).

6 Inokoshi, J. et al. Spirohexalines, new inhibitors of bacterial undecaprenyl pyrophosphate synthase, produced by Penicillium brasilianum FKI-3368. J. Antibiot. 66, 37-41 (2013)

7 Marfori, E. C., Kajiyama, S., Fukusaki, E. \& Kobayashi, A Trichosetin, a novel tetramic acid antibiotic produced in dual culture of Trichoderma harzianum and Catharanthus roseus callus. Z Naturforsch C 57, 465-470 (2002).

8 Altschul, S. F., Gish, W., Miller, W., Myers, E. W. \& Lipman, D. J. Basic local alignment search tool. J. Mol. Biol. 215, 403-410 (1990).

9 Dictionary of Natural Products on DVD December 2011, Version 20.2. (Chapman \& Hall, CRC Press, London, 2011).

10 Vazquez, M. J., Rodriguez, B., Zapatero, C. \& Tew, D. G. Determination of phosphate in nanomolar range by an enzyme-coupling fluorescent method. Anal. Biochem. 320, 292-298 (2003).

11 Vesonder, R. F., Tjarks, L. W., Rohwedder, W. K., Burmeister, H. R. \& Laugal, J. A Equisetin, an antibiotic from Fusarium equiseti NRRL 5537, identified as a derivative of N-methyl-2,4-pyrollidone. J. Antibiot. 32, 759-761 (1979).

12 Lang, G., Blunt, J. W., Cummings, N. J., Cole, A. L. \& Munro, M. H. Paecilosetin, a new bioactive fungal metabolite from a New Zealand isolate of Paecilomyces farinosus. J. Nat. Prod. 68, 810-811 (2005) 
13 Singh, S. et al. Equisetin and a novel opposite stereochemical homolog phomasetin, two fungal metabolites as inhibitors of HIV-1 integrase. Tetrahedron Lett. 39, 2243-2246 (1998).

14 Sugie, Y. et al. CJ-21,058, a new SecA inhibitor isolated from a fungus. J. Antibiot. (Tokyo) 55, 25-29 (2002).

15 Marfori, E. C., Kajiyama, S., Fukusaki, E. \& Kobayashi, A. Phytotoxicity of the tetramic acid metabolite trichosetin. Phytochemistry 62, 715-721 (2003).

16 Hazuda, D. et al. Isolation and characterization of novel human immunodeficiency virus integrase inhibitors from fungal metabolites. Antivir. Chem. Chemother. 10, 63-70 (1999).

17 De Clercq, E. Current lead natural products for the chemotherapy of human immunodeficiency virus (HIV) infection. Med. Res. Rev. 20, 323-349 (2000).

18 Ogura, K. \& Koyama, T. Enzymatic aspects of isoprenoid chain elongation. Chem. Rev. 98, 1263-1276 (1998)
19 Phillips, N. J., Goodwin, J. T., Fraiman, A., Cole, R. J. \& Lynn, D. G. Characterization of the fusarium toxin equisetin: the use of phenylbronates in structure assignment. J. Am. Chem. Soc. 111, 8223-8231 (1989).

20 Marfori, E. C., Banba, M., Kajiyama, S., Fukusaki, E. \& Kobayashi, A. Biosynthetic studies of the tetramic acid antibiotic trichosetin. Tetrahedron 58, 6655-6658 (2002).

21 Stickings, C. E. \& Townsend, R. J. Studies in the biochemistry micro-organisms. Biochem. J. 78, 412-418 (1961).

22 Kornerup, A. \& Wanscher, J. H. Methuen Handbook of Colour. 3rd edn (Eyre Methuen, London, 1978).

23 White, T. J., Bruns, T., Lee, S. \& Taylor, J. In: PCR Protocols: A Guide to Methods and Applications (eds Innis, M. A., Gelfand, D. H., Sninsky, J. J. \& White, T. J.) (Academic Press, New York 315-322, 1990).

24 Fukuda, T., Matsumoto, A., Takahashi, Y., Tomoda, H. \& Omura, S. Phenatic acids A and $\mathrm{B}$, new potentiators of antifungal miconazole activity produced by Streptomyces sp. K03-0132. J. Antibiot. 58, 252-259 (2005). 